\title{
New Design of Biopharmaceuticals through the Use of Microalgae Addressed to Global Geopolitical and Economic Changes. Are You Ready for New Development in Biopharma?
}

\author{
Armen B. Avagyan \\ Research \& Industry Center of Photosynthesizing Organisms, Feed Additives and Physiologically Active Compounds, Yerevan, Armenia. \\ Email: armin.av@hotmail.com
}

Received May $6^{\text {th }}, 2010$; accepted July $8^{\text {th }}, 2010$.

\begin{abstract}
The Biopharma industry is enduring sweeping change in response to the financial crisis, but one aspect of the industry that emerged relatively unscathed and that perhaps has directly benefited from the crisis is new revolutionary innovation solution. Identifying opportunities in the next wave of technologies for Biopharma, along with other policy initiatives including financial crisis actions and climate policy, will affect on manufacturing biopharmaceutical products today and in the future in cost effective manner, and will be our adequate answer addressing to global geopolitical, economic and climate changes. It also underscores the search for new approach, evidenced by trends around new formulations to serve lower income patients. Microalgae biomass comes in many strains, and can be used by means of variety product developments. In the last years the key task of our $R \& D$ was to find a solution for these tasks. The biofuel market development dynamics include significant opportunity of microalgae raw material and microalgae processing biomass rest of biodiesel manufacturing for Biopharma global growth in cost effective manner. Second new source of microalgae raw material for Biopharma include microalgae production through waste and wastewater cleaning. This should provide the opportunity to see the future in a new vision, where technology can serve as a revelation of the truth and where every endeavor is governed by reflection on and appreciation of the environment and thus leading to resolution of global tasks facing the world community and inclusion of microalgae in production and bio cycles open new cost effective ways for Biopharma companies and conservation of nature. A truly coherent microalgae raw material and Biopharma production policy has to find ways to bring these two traces closer for cost effective manufacturing, well being Biopharma economy and human health.
\end{abstract}

Keywords: Biopharma Development, Microalgae, Biofuel, Wastewater Cleaning

\section{Biopharma Market Development Policy}

Biopharma development progressive policy can be categorized in many different ways. The Obama administrations policies will affect the pharmacy industry going forward [1,2]. One is cost-containment track. This track has been built by legislative initiatives and key healthcare post nominations. The second is science-innovation track, powered by the economic stimulus package (\$10 billions for National Institute of Health and with prestimuus budget of more than $\$ 30$ billions) [2]. Those 10 years also witnessed the first clear signs emerging of a fundamental shift in the balance of economic and political power from West to East, as the big emerging mar- kets of Asia-and beyond-began to challenge the longstanding dominance of the U.S. and Europe. The issues identified, reimbursement challenges in emerging markets dominate the list, with potentially game-changing initiatives underway in Korea and China, and also in Japan [3]. Growth in the emerging markets is predicted $11-14 \%$ from 2008 to 2013. However, at last years, the trend has been for large pharmaceutical manufacturers to shed their consumer health divisions to narrow their business focus to a highly profitable core. As a result the last decade sales of biopharmaceutical products have grown dramatically and relatively steadily from less than $\$ 25$ billion in 2000 to nearly \$ 90 billion in 2008. At the same time, technology has created an environment for 
tremendous short- and long-term currency volatility as legions of investors can pile into or out of a currency in milliseconds. While the forces sharping the world of business are much the same-technology, population changes, natural resources, regulation, environmental concerns, political movies and social pressure-the effects of these forces are a constant state of flux, as companies learn new ways to interact with their customers. Today, process innovation is becoming as important as product innovation, because without finding better ways to promote access to needed medicines, industry's best scientific assets can never be fully leveraged to support real gains in health outcomes. The determination to find a solution may have been fueled in part by desperationand the fact that the world had just been dealt a sobering slap in the face by the financial crisis. It also underscores the search for new approach, evidenced by trends around new formulations to serve lower income patients. What will happen to the innovative category of drugs and raw materials that have been eligible for sale at a competitive low price? What is certain is that the shotgun approach belongs to the past, while precision focus and selectivity are taking hold across the industry. But many leading pharma manufacturers have been shaken out of their inertia when it comes to the existing R \& D focus and the sales of biopharmaceutical product faced with a triple hammy of declining R \& D productivity and increasing pricing forward looking companies must embracing new outsourcing strategies to achieve and maintain profitable growth $[2,4,5]$. Technology must been key factor in new changes. Nowadays we need a series of new R \& D solutions for Biopharma, which may be well advised to view portfolios of R \& D-based manufacturers from a new perspective. The world could actually enhance economic output and welfare by pursuing a path of mitigation cost through profitable innovation. This creates both new opportunities and new headaches. Brainstorming is a useful way of generating radical solutions to problems and its effective strategies is prime the pump and improve ability to generate bright ideas. It is particularly useful when you want to break out of stale, established patterns of thinking, so that you can develop new ways of looking at things. This article present situtional analyses and our approch in the framework of our concept addressed to global sustainable development through including microalgae and its biomass in Production (such as wastewater treatment and biofuel manufacturing) and Bio Cycles (such as biopharmaceuticals, feed, perfumery etc. productions) [6,7].

\section{Biopharma Project-Thinking to the Future}

The Biopharma industry is enduring sweeping change in response to the financial crisis, but one aspect of the in- dustry that emerged relatively unscathed and that perhaps has directly benefited from the crisis is new revolutionary innovation solution. It is already clear that the world's infrastructure will change dramatically in the decade ahead as a result of trends already in place. In analyzing supply and demand for bio-manufacturing capacity, we able to identify and track industry-wide trends in production of biopharmaceutical products and to forecast future directions for this highly dynamic field. The level of economic development directions and the policy choices are important factors determining the nature of the problems faced Biopharma and the ways in which they are solving. Despite several decades of experience in monitoring bioreactors and refining cell culture operations, the production of safe, pure and potent biologics remains a tricly business [1-5].

Rising energy and transportation costs and impending rules on carbon emission are promoting companies to reassess their sourcing strategies. The last year ended with United Nations conference of Copenhagen in December, with many hoping for a Kyoto-style consensus to shape globally environmental policy. The countries involved failed come to a binding agreement, but instead signed the Copenhagen Accord, which pledged \$ 30 billion a year to a fund for poor countries to adapt to climate change from 2010-2012, and $\$ 100$ billion a year by 2020. The fuel economy improvements and introduction of bioetanol and biodisiel add more opportunities for Biopharma developing. Biofuel manufacturing is expected to be a new rapidly growing global market for algae biomass and increase volume of its products [8]. Our vision infers suggests that algae have emerged as one of the most promising sources especially for Biopharma development. The validity of this approach increases and confirms in the face of Biofuels Digest updated Advanced Biofuels tracking database, based on announced projects and updated company guidance tracking 56 companies with advanced biofuels projects in 13 countries [9]. According this database algal biodiesel volume projected to reach 421 million gallons per year in 2013. The biofuel market development dynamics include significant opportunity of microalgae raw material for Biopharma global growth in cost effective manner and new technological innovation leading to the ability to develop a roll-out platform.

Second new source of microalgae raw material for Biopharma. The EU Landfill Directive has forced waste management policies across the member states of the EU to reduce the amount of waste sent for disposal in landfill. The directive requires that progressively increasing quantities of biologically active waste are diverted away from landfill. May be the criteria of the Landfill Directive can become the main drivers for the use microalgae aimed to cleaning their wastewaters in Biopharma? It is 
known that the biological method is considered the most effective and economically efficient method for the purification of industrial wastewater by using of the microbiological active slime or alga. However, bacteria of the active slime have low stability to high concentration of organic and mineral components, thus considering big water flow volumes $[7,10]$. This method also requires further destruction of superfluous quantity of active slime, which contains also pathogenic microorganisms. Microalgae have higher stability, which enables working in more concentrated and toxic environments. Chlorella actively utilizes mineral elements, spirits, sugar, and amino acids and as compared with active slime enables higher purification rate (up to $96-98 \%$ for organic and $80 \%$ for mineral components, accordingly). In the last years the key task of our R \& D was to find a solution for this problem, because microalgae possess higher stability, which enables their use in more concentrated and toxic environments, and our Center strategy believes also that the cost saving of raw material with the use of wastewaters through their biological cleaning will help raise the availability of microalgae biomass for biofuel, biopharmaceuticals, food, agriculture producers, thus leading to resolution of global tasks facing the world community. The Center carried out researchers for development technologies of microalgae cultivation in some wastewaters of industrial plants [8]. As a result the Center developed a cost-effective technology applying new innovative approaches in various stages of microalgae production and this technology for microalgae production may be applied all around the world. The exhaust steam and effluent gas (including greenhouse emissions) may be used for heating microalgae suspension in biotechnological pools so the biomass manufacture not will be available year-around. Simultaneously the high norms of wastewater purification from organic and mineral compounds were achieved and in parallel to this it was accompanied by sharp reduction of the bacteria contents in strongly microbiological infected biotechnilogical wastewater. Therefore receiving microalgae biomass by waste and wastewater cleaning and inclusion it in bio cycles open new cost effective way for Biopharma companies and conservation of nature. This should provide the opportunity to see the future in a new vision, where technology can serve as a revelation of the truth and where every endeavor is governed by reflection on and appreciation of the environment and thus leading to resolution of global tasks facing the world community. Thus, manufacturing microalgae through the use and purification of wastewaters, as well as microalgae processing biomass rest of biodiesel manufacturing must be ways for manufacturing biopharmaceutical in cost effective manner and an additional source of profit.

\section{Which Value Can Obtain Biopharma from Microalgae Biomass?}

Microalgae are a diverse group of microscopic plants with the wide range of physiological and biochemical characteristics and contain up to $50-70 \%$ protein (up to $50 \%$ in meat, and $15-17 \%$ in wheat), $30 \%$ lipids, over $40 \%$ glycerol, up to $8-14 \%$ carotene and a fairly high concentration of vitamins $B_{1}, B_{2}, B_{3}, B_{6}, B_{12}, E, K, D$, etc., compared with other plants or animals [11]. Moreover, microalgae are meant to be an important raw material for amino acids, vitamins and productions of other pharmateuticals. The cultivation of microalgae is known to be the most profitable business in the biotechnological industry. It is a wasteless, ecologically pure, energy and resource saving process. They are also harvested very quickly; dramatically speeding up production process with small water consumption. Additionally algae can adsorb up to 450 tons of $\mathrm{CO}_{2}$ per acre when grown commercially.

The potential of microalgae biomass for big Pharma practical uses is certainly great. The first use of microalgae by humans dates back 2000 years to the Chinese, who used Nostoc to survive during famine. At present around 110 commercial producers of microalgae are in the Asia-Pacific region, with annual production capacity ranging from 3 to 500 tones [12]. The commercially cultivated microalgae include Chlorella, Spirulina, $\mathrm{Du}$ naliella, Nannochloris, Nitzschia, Crypthecodinium, Schizochytrium, Tetraselmis, Skeletonema etc. The market survey shows that being developed in the last 20-30 years, the microalgae production volume increased excessively [10]. In fact, the former USSR was the first to become a large scale manufacturing of microalgae, in the framework of producing high quality feed additives [11]. In 1980 more than 500 Chlorella manufacturings were in farms of Uzbekistan (mainly for sheep, adding 1 liter microalgae suspension in the daily diet of sheep increased their weight gain by $15-20 \%$ ) as well as addiitional facielties in other Soviet republics. Chlorella powder raised the poultry the average daily weight by $13 \%$, egg-laying quality by $10-30 \%$ (paste-by $26-30 \%$ ), quantity of vitamins in liver increased 2-3 times and rate of poultry mortality decreased up to $7-23 \%$. Chlorella protein digestibility reached up to 85 percent. The average daily weight gain of pigs increased twice due to the use of Chlorella paste. Chlorella protein digestibility for pigs was $52-72 \%$. In our Industrial test ccombined feed with $1 \%$ of Chlorella powder (produced through cleaning of biotechnological wastewater of crystallic lysine) used on 25200 species of fishes (average weight-12.7 g). During the first 20 days the daily average weight gain increased by $20 \%$ ( $0.97 \mathrm{~g}$ in tested and $0.73 \mathrm{~g}$ in the control group), and the mortality reduced by $48 \%$ ( $0.77 \%$ and 
$1.25 \%$, respectively) [11]. However, the disintegration of the USSR has caused interruption of all these manufacturing.

Second-generation microalgae large scale manufacturing volume sharply increased due to significant influence of food, high-quality perfumery additives related industry development (the U.S. (Sun Wellness Inc., Cyanotech.Corp., etc), Japan (Yaeyama Factory, etc.). Most of the commercially produced algal biomass is being marketed as health food, in the forms of tablets and capsules. Algae and their extract are also included in noodles, wine, beverages, breakfast cereals and cosmetics. So, currently over $75 \%$ of pharmaceutical product development is generated by the food suppliment production comprising also microalgae. About $61 \%$ of Americans (spending \$ 6 billion yearly) and 43\% of Europeans use food additives.

\section{Which Role Can Microalgae and its Processing Raw Materials of the Biofuel Production and Wastewater Cleaning Take in the Production Patterns?}

Microalgae biomass comes in many strains, and can be used by means of variety product developments. Blue-green algae are a group of prokaryotes which history goes back to 2700 million years. Blue-green cyanophytes are not true algae. They have no nucleus, the structure that encloses the DNA, and no chloroplast, the structure that encloses the photosynthetic membranes, the structures that are evident in photosynthetic true algae. It was set at a level considered to be safe for human consumption. In China, Taiwan and Japan, several cyanophytes are served as a side dish and are considered a delicacy [12]. The very potent toxins produced by many solitary, filamentous or colonial aquatic cyanophytes, are responsible for an increasing number of water-related poisonings of both wildlife and people [7]. The World Health Organization has a limit on the toxin Microcystin at one part per billion (ppb). In 1998, the U. S. Environmental Protection Agency (EPA) included freshwater cyanobacteria and their toxins on the first Candidate Contaminant List (CCL) (Federal Register 1998). For this reason, the use of cyanophytes blue-green must be allow only from large producer- companies with good developed toxin control.

American Cyanotech. Corp. and Russian Convercia produce vitamin-mineral complex (pills of Spirullina) as a food additive and milk substitute [9]. It effectively removes slag's (heavy metals, radio nucleotides and leukocytes) from organism, reduces influence of irradiation, sugar and cholesterol in blood, cardiovascular diseases as well as increases immunity and improves skin condition. It is also useful for liver diseases, arthritis, asthenia and insomnia, regulates normal pregnancy and lactation and prevents accumulation of excessive weight. Natural products of microalgae are leading sources of novel molecules that have been used in the pharmaceutical and nutraceutical industries since their inception. So, product list of Cyanotech. Corp. included also natural astaxanthin BioAstin for humans, produced from Spirullina, which reviewed by the U.S. Food and Drug Administration and have up to 550 times the antioxidant activity of vitamin E and 10 times the antioxidant activity of beta-carotene, and surpasses many of the antioxidant benefits of vitamin $\mathrm{C}$ and other carotenoids [13].

Green algae evolved from prokaryotes between 2500 and 1000 million years ago. Chlorella is a microscopic, green, single cell and has not toxins. During 12 hours Chlorella cell provides fourfold reproduction of cells in optimum conditions. Compared to the traditional plants, the water consumption of manufacturing is over 10 times as low. The biomass yield per sq. are 5 times higher. Other main Chlorella biological priorities are as following [11]:

1) High concentration of protein (50\%) and amino acids,

2) High concentration of chlorophyll (5-10 times as much, compared to Spirullina or Lucerne), the molecule of which is identical to hemoglobin molecule structure. Therefore, if getting in blood flow, it sates blood with oxygen and is transformed to hemoglobin. The chlorophyll is an effective means for the treatment of anemia, a pancreatitis, skin ulcer, diabetes, recovery of peristalsis affect and normalization of digestive juice excretion. It owns anticancer, anti-inflammatory, antiseptic and regenerating properties,

3) Unique properties of a cell wall which consists of three layers (the largest-a middle part consists of cellulose, and the outer layer is formed of polymeric carotene which is capable of adsorbing toxic elements and removing them from organisms),

4) High contents of vitamins, especially, pro-vitamin A-carotene, which not only plays an important role during the growth process, but destructs cancer cells as well in initial stages and improves the generation of macrobacteriophage in immune system,

5) Ability to intensively synthesize high concentration of nucleonic acids with a combination of high contents of fibers, peptides, amino acids, other vitamins, sugars and trace elements. This not only promotes super fast reproduction of Chlorella, but as a growth factor also provides favorable conditions for the use of Chlorella in other organisms.

6) Chlorella has also organic acids, which prevent the growth of pathogenic microorganisms in wastewater and feed. While antibiotics were proven to be effective in improving agricultural production, their use came under pressure as an increasing number of consumers feared 
that their inclusion in animal feed rations would lead to antibiotic resistant bacteria that are pathogenic to humans. In 2005, the EU removed the last antibiotic growth promoters from pig and poultry diets. As consensus begins to develop among the scientific community on this subject, a few approaches stand out in terms of efficacy, technological and economical feasibility, particularly in terms of organic acids and the use of essential or botanical oils $[7,8]$. Organic acids provide a natural alternative, reducing production of toxic components by bacteria and causing a change in the morphology of the intestinal wall that reduces colonization of pathogens, thus preventing damage to the epithelial cells. Anions of organic acids deactivate the RNA transferase enzyme, which damage the nucleic acid multiplication process and eventually result in death of the organisms. But the manufacturing of organic acids and essential oils for the feed industry are potentially a source of other problems: corrosion, worker safety, handling, vitamin stability in pre-mixes, environmental concerns, and the stability of products $[8,11]$. With all this in mind, the use of microalgae Chlorella could become the best solution, since microalgae contain natural organic acids (hexadecatetraenoic (up to $7-8 \%$ of total fatty acid quantity) and octadecatetraenoic acids, as well as oxy, aldehyde and keto acids, which increase spectrum of antibacterial action) that reduce colonization of pathogens. Therefore, thanks to this feature Chlorella is also used for feed conservation, and the reduction of microbiological pollution of wastewaters.

Chlorella studies have shown the plant's cells are proactive in stimulating T-cells, and largely improving the immune system's ability to ward off the formation of diseases like cancer, hypoglycemia, and bacteria [14]. Chlorella's high concentration of chlorophyll has been cited to eliminate halitosis in a matter of just days and after reversing constipation, Chlorella can improve the stink of heavily accented stools.

In the end of 1990 in former USSR clinical tests examined Lipid concentrate of Chlorella (for the treatment of colitis, cervical erosion and burn) and Chlorella hydrolysate (for the improvement of working capasity). According to all-Union State Standards of the CIS countries this products can use for shampoos, creams, tooth pastes, lotions etc. as bioactive additive.

The yellow microalgae can be used as sourse of arachidonic eicosapentaenoic acids aimed to manufacturing of drugs.

The growing worldwide market value of carotenoids is projected to reach over US \$1,000 million and there the use of microalgae open possibility aimed to reduction in production costs [15]. The Israel and Australia companies specialized in carotene production from unicellular green Dunaliella microalgae (up to 8-14\% carotene, over
$40 \%$ of glycerol).

Omega-3-fatty aids can not be constructed within our bodies. Therefore they must be obtained from the diet, making outside source. DHA is found at low levels in fish and at high levels in certain microalgae oils. Concentrated omega-3 DHA dietary supplements made from microalgae oils or extracted from fish oils currently are the best way to get medical dosages of DHA at levels above 1 gram daily [16]. They extracted from algae with organic solvents from protein while the fish oil is pressed out of cooked fish mass during fishmeal production. In California, BioCentric Energy Holdings announced the commercialization of its closed-loop Photo-Bioreactor system for the mass production and subsequent comercialization of algae products for Omega-3 (EPA) oil and algal biomass [17].

Recitals of the experience gained on microalgae use may continue, but the above discussion demonstrates an increasing need to the use of microalgae in Biopharma. Identifying opportunities in the next wave of technologies for Biopharma, along with other policy initiatives including financial crisis actions and climate policy, will affect on manufacturing biopharmaceutical products today and in the future in cost effective manner, and will be our adequate answer addressing to global geopolitical, economic and climate changes. A truly coherent microalgae raw material and Biopharma production policy has to find ways to bring these two traces closer for cost effective manufacturing, well being Biopharma economy and human health. Further isolation and identification of novel metabolites from microalgae will help to feed the pipeline of the biopharmaceutical industries for the development of new therapeutic agents, but also open a door for nutraceutical and functional food industries.

\section{REFERENCES}

[1] J. Wechdier, "Issue and Opportunities Challenge Biotech Manufacturers,” Biopharm International, Vol. 23, No. 1, 2010, pp. 16-17.

[2] M. Hoffman, "Parallel Track. Obama Cost-Containment and Science Innovation Initiatives Need to Overlap," Pharmateuticals Technology, Vol. 33, No. 4, April, 2009, p. 12.

[3] E. C. Langer, M. Pavicant, "Global Economic Crunch. Benefits Biomanufacturing Outsourcing to Asia,” Inside Outsoursing, November 2009, pp. 24-28.

[4] D. C. Esola, “An Introduction from the Publisher,” Inside Outsoursing, November 2009, p. 8. http://www.nxtbook. com/nxtbooks/advanstar/insideoutsourcing_200911/\#/10/ OnePage.

[5] A. C. Cacich, R. Bjella, M. J. Cosko, et al., "8 Key Players. On The Future of Global Outsourcing, and Forming Alliances with CRO's/CMO's," Inside Outsoursing, November 2009, pp. 32-37. 
http://www.nxtbook.com/nxt-books/advanstar/insideoutsou rcing_200911/\#/32/OnePage.

[6] A. B. Avagyan, “A Contribution to Global Sustainable Development: Inclusion of Microalgae and their Biomass in Production and Bio Cycles," Clean Technologies and Environmental Policy, Vol. 10, No. 4, 2008, pp. 313-317.

[7] A. B. Avagyan, "New Design \& Build Biological System through the Use of Microalgae Addressed to Sustainable Development," Journal of Environmental Protection, Vol. 1, No. 2, 2010, pp. 183-200.

[8] A. B. Avagyan, "Global Prospects for Microalgae Production for Biofuels and for the Preservation of Nature," Global Fuel Magazine, February 2008, pp. 22-27. http://www.propubs.com/global-fuels/eGF_Feb08_LowRe s.pdf

[9] J. Lane, “Advanced Biofuels Tracking Database,” Biofuels Digest, March 2010. http://www.biofuelsdigest.com/bdigest/2010/03/23/advanced-biofuels-tracking-database/

[10] A. B. Avagyan, "Microalgae Production Development Global Prospects and Profitable Technology Wasterwater Purification by the Use Microalgae,” Water and Wastewater International, 2008. http://ww.pennnet.com/articles/article_ display.cfm?article_id=340236\&dcmp=WaterWorldEnl

[11] A. B. Avagyan, "Microalgae: Big Feed Potential in a Small Package,” Feed International, March 2008, pp. 16-18. http://www.fi-digital.com/fi/200803/data/feedinternationa 1200803-win32.zip

[12] Y.-K. Lee, "Commercial Production of Microalgae in the Asia-Pacific Rim,” Journal of Applied Phycology, Vol. 9, No. 5, October 1997, pp. 403-411.

[13] Cyanotech Corp.,"BioAstin.”, http://www.cyanotech.com/bioastin.html

[14] The Colon Cleansing \& Constipation Resource Center, "How Chlorella Relates to Constipation," 2007. http://www.articlesbase.com/alternative-medicine-articles /how-chlorella-relates-to-constipation-89878.html

[15] J. A. Del Campo, M. García-González, M. G. Guerrero, "Outdoor Cultivation of Microalgae for Carotenoid Production: Current State and Perspectives,” Applied Microbiology and Biotechnology, Vol. 74, No. 6, 2007, pp. 11631174.

[16] H. Chapell, "PhD Presents Omega-3 Replacements for Medical Fish Oils,” February 2009. http://www.chiroeco. com/chiropractic/news/7480/856/PhD-presents-Omega-3replacements-for-medical-fish-oils/

[17] J. Lane, "BioCentric to Deploy Five Algae Photobioreactor Units in Client Trial,” Biofuels Digest, April 2010. http://biofuelsdigest.com/bdigest/2010/04/23/biocentric-t o-deploy-five-algae-photobioreactor-units-in-client-trial/ 